\title{
The optimisation of biscuit formulation with grape and aronia pomace powders as cocoa substitutes
}

\author{
Dunja Molnar ${ }^{1}$, Dubravka Novotni ${ }^{*}$, Judith Krisch ${ }^{2}$, Tomislav Bosiljkov ${ }^{1}$, Mario Ščetar $^{1}$ \\ ${ }^{1}$ University of Zagreb, Faculty of Food Technology and Biotechnology, Pierottijeva 6, 10000 Zagreb, Croatia \\ ${ }^{2}$ Institute of Food Engineering, University of Szeged, 6724 Szeged, Mars tér 7, Hungary \\ *Corresponding author: dubravka.novotni@pbf.unizg.hr
}

\begin{abstract}
By-products of fruit processing, such as grapes and aronia pomace, are rich in fibre and polyphenols, and their application in bakery products could significantly improve nutritional value, bioactive potential and shelf life of final product. This research aimed at optimising wholemeal biscuit formulation with grape and aronia pomaces as partial substitutes for cocoa powder, using the desirability function. Ten formulations with the mixture of cocoa powder, grape and aronia pomace powders in different ratios (0-100\%) were tested. The physical properties (texture, colour, thickness, diameter, spread factor), the sensory acceptability of biscuits, and microbiological safety were investigated. The interaction of all three mixture components significantly affected the instrumentally measured redness $a^{*}$ and liking of texture. Biscuit diameter, yellowness $b^{*}$, and liking of flavour were affected by the interaction of aronia and grape pomace. Biscuit height, spread ratio, hardness, flexibility, toughness, appearance, and odour were not significantly influenced by the mixture composition. The optimized mixture composition contained cocoa, grape pomace, and aronia pomace in the ratio $76.4: 17.5: 6.1$ (respectively), with the desirability of 0.78 . After confirmation, biscuits with that mixture were proven better than the control, that contained 100\% cocoa, in terms of decreased hardness (-23\%) and toughness (-19\%), having the same sensory acceptability, and were microbiologically safe for 5 months. The findings of this study indicate that aronia and grape pomace could be used as partial substitutes for cocoa powder up to $24.3 \%$ in the production of wholemeal biscuits.
\end{abstract}

Keywords: aronia pomace, grape pomace, biscuit formulation optimisation, cocoa substitute

\section{Introduction}

Biscuits are popular cereal based products, due to their rich nutrition content, different shapes and flavours, ready-to-eat form, and long shelf life (Ajila et al., 2008). They are known as indulgent food although there is growing interest in healthier and functional biscuits (Crofton et al., 2013; Konstantas et al., 2019). Biscuits could be used as medium for incorporation of various ingredients and nutrients into the diet (Čukelj et al., 2016) such as dietary fibre, proteins, vitamins, minerals, polyphenols, $\beta$-glucans, and sterols.

Cocoa powder is one of the most popular additional ingredients in bakery industry due to its unique flavour (Manley, 2000; Loullis and Pinakoulaki, 2018). Demand for cocoa is continuously increasing, and it is very likely that the production will not be able to maintain with demand, which would lead to the rise of cocoa price (Loullis and Pinakoulaki, 2018). Moreover, biscuits containing chocolate/cocoa are environmentally the least sustainable in terms of cocoa production (Konstantas et al., 2019). These are the reasons why finding a replacement for cocoa is becoming an imperative. Many studies investigated the substitutes for cocoa butter, but there is only a limited number of studies trying to find substitution for cocoa powder (Barroso et al., 2015, Rosa et al., 2015; Fadel et al., 2006). The main limitation of commercially available imitation cocoa powders based on starch, legumes, soy flour, chicory root, chocolate flavour, and different additives is that they differ significantly from natural cocoa powder, mostly in colour, water solubility and chemical composition (Rikon and de Valle, 1982). Most recent studies showed that carob powder may be successfully used as low-cost cocoa substitute (Pawlowska et al., 2018; Loullis and Pinakoulaki, 2018). Carob flour may substitute up to $30 \%$ of the cocoa powder in biscuits without appreciable change in flavour (Manley, 2000). Similar to cocoa, carob flour contains various phytochemicals but is also rich in condensed tannins which tend to give an astringent aftertaste to products (Loullis and Pinakoulaki, 2018; Silanikove et al., 2006). Thus, finding a cocoa substitute with better sensory characteristics is needed.

Dried fruits (grapes in particular) are common, but rather expensive raw material for making biscuits. Recently, fruit pomaces from wine industry such as white grape pomace (Mildner-Szkudlarz et al., 2013) and red grape pomace (Acun and Gül, 2014), as well as pomaces from juice industry, such as apple pomace (Singh et al., 2012) and blueberry pomace (Curutchet et al., 2019) were suggested as alternative sources of dietary fibre and phenolics for the novel formulation of biscuits. Pomace may account from $20 \%$ up to $50 \%$ of the original fruit weight (Khanal et al., 2009) and is disposed as waste from juice and wine industry. The disposal of such waste materials is environmentally and economically problematic (Palocci and Chronopoulou, 2015). Growing interest has been raised to safe disposing of fruit processing waste and recovering of valuable compounds such as phenolics and dietary fibre remained in the by-products (Galanakis, 2012; Khanal et al., 2009). Nevertheless, pomaces being a rich source of valuable components, could be used as low-cost functional ingredients in food production (Galanakis, 2012; Karnopp et al., 2015; Prokopov et al., 2015). To our knowledge, the potential of using red grape and aronia pomaces as partial cocoa substitutes for making biscuits formulation with great sensory and physical properties has not been investigated yet. Thus, this research aimed to optimize the wholemeal biscuit formulation with powdered grape and aronia pomaces as partial substitutes for cocoa powder using a mixture design and desirability function. The pomaces were finely ground to approximate particle size of the cocoa powder. Physical and sensory properties as well as the microbiological safety of biscuits were determined. 


\section{Materials and methods}

\section{Raw materials}

Wholemeal spelt flour (Siladi, Croatia) containing $12 \%$ protein and fine oat flakes (Crownfield, Germany) containing 13.5\% proteins were bought on a local market. Cocoa powder (Kraš, Croatia) contained $20 \%$ fat and margarine (with butter) contained $70 \%$ fat (Zvijezda, Croatia). Dried red grape (Vitis vinifera, Frankovka and Syrah variety, with seeds) pomace and aronia (Aronia melanocarpa, without seeds) pomace were obtained as by-products from juice production from local producers (Natkrižovljan, Cestica Community and Demit, Dugo Selo, Croatia, respectively). The following properties were taken into account: dark colour, high antioxidant capacity, and good flavour. The moisture level was below $10 \%$. Dried grape and aronia pomace were ground in a laboratory ball mill (Cryomill, Retsch, Austria), in order to reach the average particle size assembling to cocoa powder. Pomaces $(7 \mathrm{~g})$ were 3 min ground in a $50 \mathrm{~mL}$ stainless steel container with 12 steel balls $(10 \mathrm{~mm}$ diameter), and vibration frequency of $30 \mathrm{~Hz}$. Particle size distribution of cocoa powder and ground pomaces was determined in triplicates by laser diffraction method with Malvern Mastersizer 2000 instrument and a Scirocco 2000 dry dispersion unit (Malvern Instruments Ltd., UK). The mean particle size distribution of cocoa, grape and aronia pomaces powder is shown on Figure 1. The median diameter of 50th percentile of cocoa powder was $41 \pm 3 \mu \mathrm{m}$, grape pomace powder $37 \pm 2 \mu \mathrm{m}$ and aronia pomace powder $35 \pm 3 \mu \mathrm{m}$.

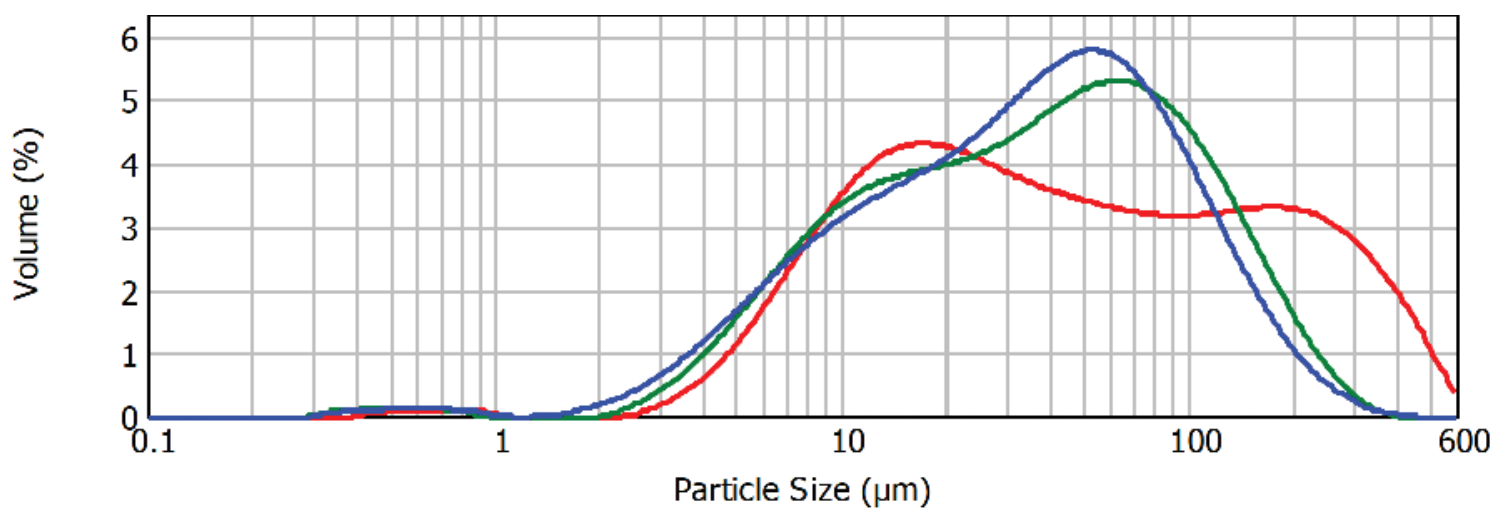

Figure 1. Particle size distribution of cocoa powder (red line), grape (green line) and aronia (blue line) pomace powder

\section{Experimental design and biscuit formulation}

Ten formulations were prepared according to mixture design using Design Expert v.11 software (Stat-Ease, USA). The following formulation for the control biscuit $(100 \%$ cocoa) was designed in preliminary experiments (weight on total dough weight, in percentage): fine oat flakes $30 \%$; wholemeal spelt flour $25.2 \%$; margarine $20 \%$; brown sugar $13.5 \%$; cocoa powder $4.8 \%$; vanilla sugar $3.5 \%$; salt $2 \%$; tap water $0.4 \%$; baking powder $0.3 \%$; sodium bicarbonate $0.3 \%$. Cocoa powder was completely or partially replaced with grape and/or aronia pomace powder in different ratios (0-100\%) (Table 1). Biscuits were made according to AACC (1999) method 10-50.05. Dough was prepared by mixing all the ingredients together, and then it was rolled out to thickness of $5 \mathrm{~mm}$ and shaped with round cutter $5 \mathrm{~cm}$ diameter. Thirty pieces of each biscuit formulation were baked in two batches in an oven at $180^{\circ} \mathrm{C}$ for 12 minutes. Biscuits were cooled and packed in biaxially oriented polypropylene (BOPP) coated with acrylic/polyvinylidene chloride (AcPVDC) to obtain composite $32 \mu \mathrm{m}$ thick BOPPAcPVDC film (ExxonMobil, Belgium). Pouches with biscuits were hermetically sealed using welding machines Audion Sealkid 421 (Viro, Croatia) and stored at room temperature $\left(22^{\circ} \mathrm{C} \pm 1{ }^{\circ} \mathrm{C}\right)$ for analyses.

\section{Determination of biscuit physical characteristics}

Biscuit physical characteristics were determined the day after baking in at least 10 replicates. The diameter was measured with a calliper across the biscuit length, height was measured on 6 biscuits stacked together and biscuit spread factor was calculated following AACC 10-50.05 (1999). Texture was determined with HD.Plus Texture Analyser using three point bending rig with HDP/3PB knife-edge probe, and 30-kg load cell (Stable Micro System, UK). The analysis was performed with a test speed of $2 \mathrm{~mm} / \mathrm{sec}$ and distance of $5 \mathrm{~mm}$. Hardness, flexibility and toughness were calculated according to American Institute of Baking (AIB) protocol. The colour of biscuit's upper surface was measured using a calibrated spectrophotometer Model CM-3500d (Konica Minolta, Japan). The $L^{*}, a^{*}, b^{*}$ components of the CIELab space were recorded, where $L^{*}$ indicates lightness $\left(\mathrm{L}=0\right.$ (black), $\mathrm{L}=100$ (white), $a^{*}$ indicates chromaticity on a green $(-)$ to red $(+)$ axis, and $b^{*}$ chromaticity on a blue $(-)$ to yellow $(+)$ axis. Colour difference $(\mathrm{dE})$ from the control sample (100\% cocoa) was calculated according to Pathare et al. (2013): $\mathrm{dE}=\left((\Delta \mathrm{L})^{2}+(\Delta \mathrm{a})^{2}+(\Delta \mathrm{b})^{2}\right)^{1 / 2}$.

\section{Sensory analysis}

Nine-point hedonic scale (Svensson, 2012) was used to evaluate biscuits appearance, odour, flavour, texture, and overall acceptability; with 1 dislike extremely and 9 like extremely. Sensory evaluations were carried out in two different sessions. In the first session, experienced panellists ( 9 female and 2 male) were asked to evaluate ten formulations of biscuits with the mixture of cocoa powder, grape and aronia pomace powders in different ratios $(0-100 \%)$. In the second session, 27 female and 10 male untrained panellists, using the same nine-point hedonic scale, determined how they liked the biscuits with optimized mixture composition and the control. For all sessions, biscuits were coded with numbers on a white plate and cold tap water was provided for cleansing palate before tasting each sample. Each panellist received whole biscuits on a plate.

\section{Microbiological analysis of biscuits}

The microbiology of the control and optimized biscuits was examined in five parallel determinations according to the Commission regulation (EC) No 2073/2005 on microbiological criteria for foodstuffs and 
Croatian National Guidelines on microbiological criteria for food stuffs (2011). Microbiological analyses were done for seven months in order to determine the shelf life of biscuits. Total cell number was determined by plate count method on plate count agar (peptone $5 \mathrm{~g}$, glucose $10 \mathrm{~g}$, yeast extract $2.5 \mathrm{~g}$, agar - agar $25 \mathrm{~g}$ in $1000 \mathrm{ml}$ distilled water). Mould count was determined by plate count method on malt extract medium (malt extract $5 \mathrm{~g}$; yeast extract $5 \mathrm{~g}$, glucose $5 \mathrm{~g}$, agar-agar $20 \mathrm{~g}$ in $1000 \mathrm{ml}$ distilled water). Coagulase positive Staphylococcus was determined by plate count method on Baird-Parker agar (Sigma-Aldrich, Hungary). The presence of Enterobacteriaceae was determined in Brillant Green Bile Lactose broth (Sigma-Aldrich, Hungary). The number of Salmonella was determined according to ISO 6579-1:2017.

\section{Data analyses and formulation optimisation}

Design Expert v.11 (Stat-Ease, USA) software was used to generate the experimental design, evaluate raw data by analysis of variance (ANOVA) at $\mathrm{p}<0.05$, and the numerical optimisation using desirability function. Different models were tested for their ability to fit the experimental response values, and the backward elimination procedure $(p<0.05)$ was conducted for fitting the experimental data. The criteria for optimisation were to minimise hardness and colour difference (with importance 3 ) and to maximise diameter (importance 1), taste, odour and texture (importance 5) as well as overall acceptability of biscuits (importance 3 ) in order to develop biscuits with the most similar sensory properties as biscuits with $100 \%$ cocoa powder. The same quality parameters were determined for the biscuit baked with the optimised mixture of cocoa, grape and aronia pomace powders as for the control (100\% cocoa). After confirmation experiment, the prediction error (\%) was calculated as (experimental - predicted) / predicted $\times 100$.

\section{Results and discussion}

\section{Physical characteristics of biscuits}

The physical characteristics of biscuits formulations with different cocoa powder, grape and aronia pomace powders ratios are presented in table 1. Higher spread factor (higher diameter and lower height) is considered a positive biscuit characteristic. Still, diameter and height are better for estimation of quality than spread ratio since diameter and height can vary in different ways giving the same spread factor (AACC Standard No 10-50.05, 1999). Biscuit height and spread ratio were not significantly $(\mathrm{p}>0.05)$ influenced by the mixture composition, but biscuit diameter was negatively affected $(\mathrm{p}<0.05)$ depending on the linear and nonlinear interactions between aronia and grape pomace, and aronia and cocoa (Figure 2a, Table 2). In accordance with our results, Karnopp et al. (2015) found no significant difference in spread ratio of biscuits with added grape pomace (up to 30\%). Ajila et al. (2008) reported a decrease in the diameter but also in the thickness of biscuits with addition of $15 \%$ or $20 \%$ mango peel powder. Dissimilar, Acun and Gül (2014) found that there was no significant difference between diameters of biscuits with added white grape pomace and Mildner-Szkudlarz et al. (2013) found an increase in diameter and spread ratio of biscuits with incorporated white grape pomace. Different findings of pomace effect on biscuits diameter could be due to differences in pomace type, amount and composition used as well as in fat sugar and fibre content of other ingredients used for making biscuit (Mamat and Hill, 2018).

Colour is one of the key factors affecting consumer's choice and preferences regarding biscuit acceptability (Chakraborty et al., 2010). The colour of biscuits is influenced by the formulation as well as by the caramelization, dextrinization and Maillard reactions that occur during the baking process (Walker et al., 2014). The interaction of grape and aronia pomace powders significantly influenced $L^{*}$ values $(\mathrm{p}=0.004)$ (Table 2). When grape pomace composed at least $50 \%$ of the mixture, $L^{*}$ value was higher which means that biscuits became lighter than the

Table 1. Mixture composition and physical properties of biscuits with the mixture of cocoa powder, grape and aronia pomace powders in different ratios

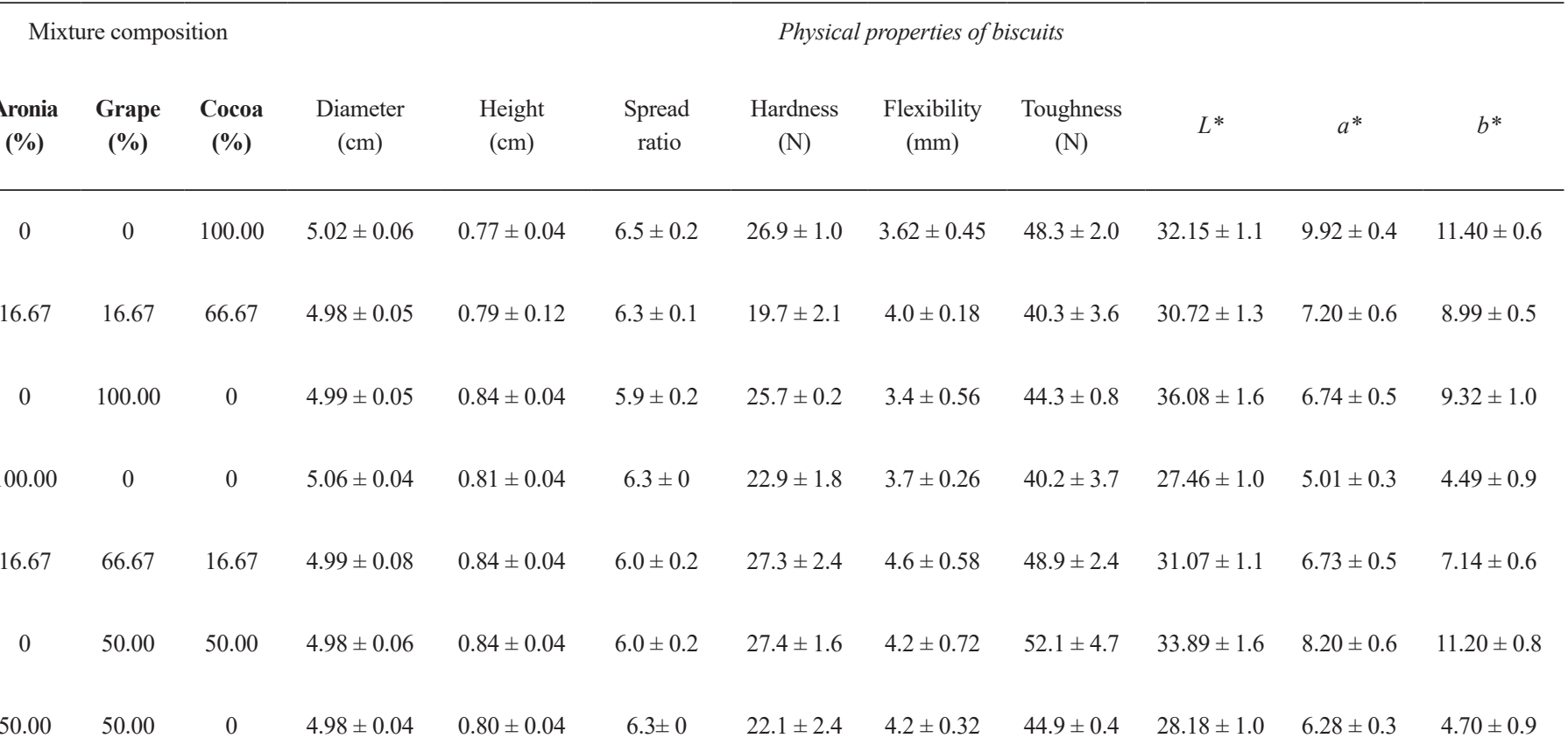




$\begin{array}{cccccccccccccccccc}50.00 & 0 & 50.00 & 4.95 \pm 0.03 & 0.84 \pm 0.04 & 5.9 \pm 0.2 & 26.9 \pm 1.0 & 3.6 \pm 0.79 & 47.2 \pm 1.2 & 29.62 \pm 1.8 & 5.14 \pm 0.5 & 6.50 \pm 1.0 \\ 66.67 & 16.67 & 16.67 & 4.97 \pm 0.06 & 0.78 \pm 0.04 & 6.4 \pm 0.1 & 24.6 \pm 0.6 & 3.6 \pm 0.57 & 42.5 \pm 2.1 & 29.06 \pm 0.8 & 5.02 \pm 0.5 & 5.41 \pm 1.8 \\ 33.33 & 33.33 & 33.33 & 4.97 \pm 0.05 & 0.74 \pm 0.07 & 6.7 \pm 0.4 & 26.6 \pm 0.8 & 3.6 \pm 0.82 & 45.8 \pm 0.2 & 30.32 \pm 1.5 & 5.74 \pm 0.6 & 7.00 \pm 0.8\end{array}$

control sample with $100 \%$ cocoa powder. The interaction of all three mixture components (cocoa, grape and aronia pomace powders) significantly $(\mathrm{p}<0.05)$ affected $a^{*}$ and $b^{*}$ values (Table 2$)$, whose intensities were lower after adding pomaces. Similary, Acun and Gül (2014) observed that the biscuits with addition of red grape pomace and grape seed flour are darker and that grape pomace addition in biscuits led to decrease in $b^{*}$ value. Also, Karnopp et al. (2015) observed that biscuits with higher grape pomace content are darker and have lower $a^{*}$ and $b^{*}$ values. A noticed decrease in $a^{*}$ and $b^{*}$ values might be the reflection of the anthocyanins composition from pomace (Šarić et al., 2016), but also due to the fact that our control sample contained cocoa powder.

Overall, the colour difference from the control formulation $(100 \%$ cocoa) was the biggest when aronia prevailed in the mixture (Figure $2 b$ ). Our study indicates the possibility of combining fruit pomaces with different concentrations of anthocyanins to obtain desirable colour as it is in control formulation (100\% cocoa).

Hardness, toughness and flexibility of biscuits were not significantly $(p>0.05)$ affected by the mixture composition (Table 1). Hardness and toughness were significantly correlated $(\mathrm{r}=0.8)$. Contrary, Kuchtova et al. (2016) reported that biscuits with $15 \%$ grape seed powder became significantly harder compared with control sample. In previous studies the hardening effect was attributed mostly to the lower content of gluten (Karnopp et al., 2015) and the composition of fibres from the added pomaces (Šarić et al., 2016) which possess high water holding capacity resulting in harder biscuits (Turksoy and Ozkaya, 2011). In our study, the water addition was consistent between formulations, and the amount of fibre was already high since we used wholemeal flour and oat flakes.

Moreover, we used powdered pomaces, which might have shifted the fibre composition toward more soluble.

\section{Consumers liking}

The sensorial quality of food products plays an important role in the choice of food and hedonic testing are often used to determine consumer's attitude towards the food by assessing a degree of acceptance of a new product or by enhancing the existing food product (Curutchet et al., 2019). The addition of grape and aronia pomace powders significantly influenced the flavour and overall acceptability of biscuits $(\mathrm{p}<0.01)$ (Table 3). The flavour of biscuits was dependent on all mixture components and their interactions (Table 2). The addition of grape and aronia pomace powders had positive impact on biscuits flavour, despite of their fruity taste, although cocoa powder had the greatest impact on liking the flavour (Figure 2c). The liking of texture was significantly $(p<0.05)$ influenced by the interaction of all mixture components (Tables 2 and 3). The balanced replacement of cocoa with both grape and aronia in small amounts (up to $30 \%$ ) positively influenced the liking of texture. Just like a flavour, the overall acceptability of biscuits was the highest when cocoa prevailed in the mixture, whereas the lowest when aronia prevailed (Figure 2d). The odour and appearance were no significantly different between biscuits $(\mathrm{p}>0.05)$. Similar effects of grape preparations on odour and appearance of biscuits were observed by Mildner-Szkudlarz (2013). In accordance with our study, Karnopp et al. (2015) showed that the addition of grape pomace in bigger amounts significantly influence the overall acceptability of biscuits and that biscuits formulation needs to be optimised in order to stimulate consumption.
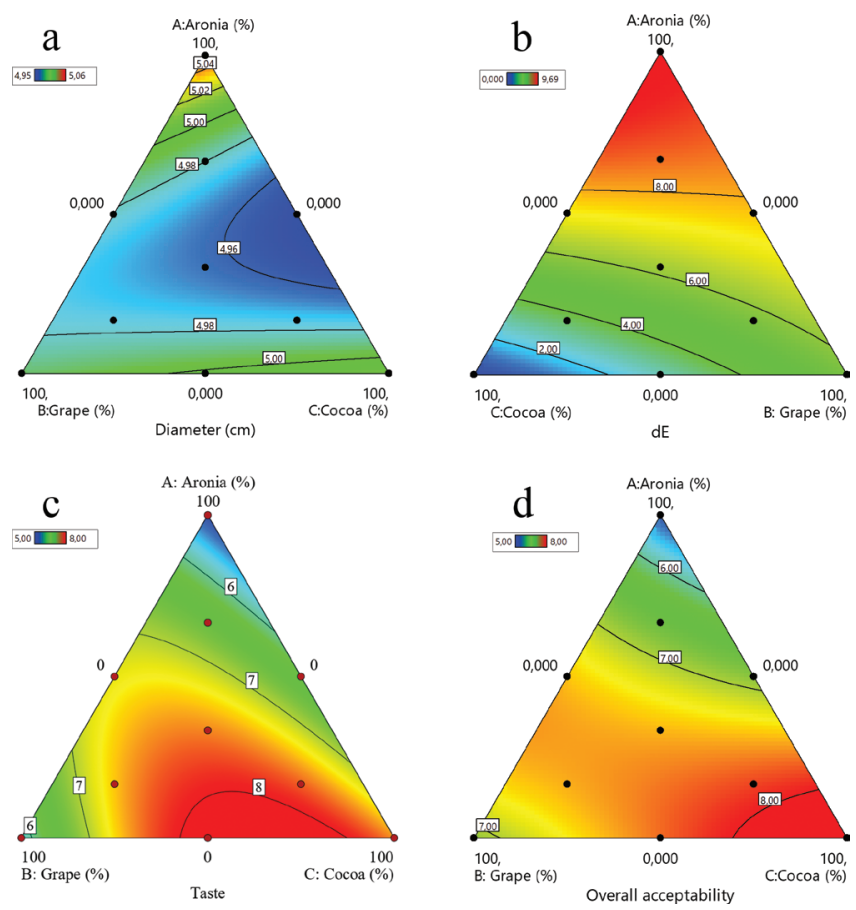

Figure 2. Contour plots of selected responses (biscuits diameter, colour difference, flavour, and overall acceptability) in relation to the mixture composition 
Table 2. Significant coefficients of the fitted equations for the different responses depending on the linear and nonlinear interactions between aronia pomace, grape pomace and cocoa (actual factors)

\begin{tabular}{|c|c|c|c|c|c|c|c|c|}
\hline Response & Linear mixture & $\mathbf{A} \times \mathbf{B}$ & $\mathbf{A} \times \mathbf{C}$ & $\mathbf{B} \times \mathbf{C}$ & $\mathbf{A} \times \mathbf{B} \times \mathbf{C}$ & $\mathbf{A B}^{2} \mathbf{C}$ & $\mathrm{ABC}^{2}$ & $\mathbf{R}^{2}$ \\
\hline Diameter & & -0.174 & -0.328 & & & & & 0.892 \\
\hline Flavour & $5.11 \times \mathrm{A}+5.79 \times \mathrm{B}+7.57 \times \mathrm{C}$ & 7.042 & & 5.951 & & & & 0.909 \\
\hline Texture & $6.51 \times A+6.97 \times B+7.01 \times C$ & 2.993 & 1.051 & & -7.941 & & & 0.784 \\
\hline Overall acceptability & $5.22 \times A+6.89 \times B+8.49 \times C$ & 5.451 & & & & & & 0.858 \\
\hline Lightness $L^{*}$ & $26.38 \times A+34.22 \times B+31.97 \times C$ & & & & & & & 0.955 \\
\hline Redness $a^{*}$ & $5.02 \times A+6.78 \times B+9.90 \times C$ & 1.683 & -9.349 & & -14.313 & & & 0.984 \\
\hline Yellowness $b^{*}$ & $4.70 \times A+9.14 \times B+11.36 \times C$ & -9.300 & -5.950 & & & & & 0.977 \\
\hline Colour difference $\mathrm{dE}$ & $9.95 \times A+5.60 \times B-0.03 \times C$ & & 9.473 & & & & & 0.986 \\
\hline
\end{tabular}

Note: bold significant at $p<0.001$; regular $p<0.05$; italic $p<0.010$; A, aronia; $B$, grape; $C$, cocoa.

Table 3. Results of sensory analysis of biscuits with the mixture of cocoa powder, grape and aronia pomace in different ratios

Mixture composition

Aronia

(\%)

\begin{tabular}{cccccccc}
\hline 0 & 0 & 100.00 & $8 \pm 0.7$ & $8 \pm 1.8$ & $8 \pm 1.6$ & $7 \pm 1.9$ & $8 \pm 0.6$ \\
16.67 & 16.67 & 66.67 & $7 \pm 1.1$ & $8 \pm 1.2$ & $8 \pm 0.3$ & $7 \pm 1.0$ & $8 \pm 0.8$ \\
0 & 100.00 & 0 & $7 \pm 1.7$ & $7 \pm 1.2$ & $6 \pm 1.2$ & $7 \pm 0$ & $6 \pm 1.1$ \\
100.00 & 0 & 0 & $7 \pm 1.3$ & $7 \pm 1.2$ & $5 \pm 2.7$ & $7 \pm 2.1$ & $5 \pm 2.5$ \\
16.67 & 66.67 & 16.67 & $7 \pm 0.9$ & $7 \pm 1.2$ & $7 \pm 0.5$ & $7 \pm 1.6$ & $8 \pm 0.8$ \\
0 & 50.00 & 50.00 & $8 \pm 0.8$ & $9 \pm 0.7$ & $8 \pm 0.6$ & $7 \pm 1.4$ & $8 \pm 0.9$ \\
50.00 & 50.00 & 0 & $8 \pm 0$ & $8 \pm 1.3$ & $7 \pm 1.4$ & $8 \pm 1.4$ & $7 \pm 1.3$ \\
50.00 & 0 & 50.00 & $8 \pm 0.9$ & $8 \pm 1.7$ & $6 \pm 1.5$ & $7 \pm 1.8$ & $7 \pm 1.2$ \\
66.67 & 16.67 & 16.67 & $8 \pm 0.6$ & $7 \pm 1.2$ & $7 \pm 0.6$ & $7 \pm 1.3$ & $7 \pm 0.8$ \\
33.33 & 33.33 & 33.33 & $8 \pm 0.5$ & $8 \pm 1.0$ & $8 \pm 0.6$ & $7 \pm 1.0$ & $8 \pm 0.8$ \\
\hline
\end{tabular}

Grape (\%)

$\operatorname{Cocoa}(\%)$

$\operatorname{Cocoa}(\%)$

Appearance

Odour

Sensory properties of biscuits

\section{Formulation optimisation and validation}

The optimised mixture composition with a desirability of 0.725 was: cocoa powder $76.4 \%$, grape pomace $17.5 \%$ and aronia pomace $6.1 \%$. The model prediction of properties of biscuits made with optimised mixture were: diameter $4.99 \mathrm{~cm}$, height $0.66 \mathrm{~cm}$, spread ratio 7.56 , hardness 23.6 $\mathrm{N}$, flexibility $3.8 \mathrm{~mm}$, toughness $47.3 \mathrm{~N}$, colour $L^{*} 32.02, a^{*} 8.45, b^{*}$ 10.51, appearance 8 , flavour 8 , texture 8 , and overall acceptability 8 . After baking biscuits with the optimized mixture composition, measured values were in good agreement with predicted values (with prediction error in brackets) for diameter $4.95 \mathrm{~cm}(-1 \%), L^{*} 31.01(-3 \%), a^{*} 7.91$ $(-6 \%), b^{*} 9.82(-7 \%)$, appearance $8(-2 \%)$, flavour $8(-2 \%)$, liking of texture $8(0 \%)$ and overall acceptability $8(-1 \%)$. Although the models were nonsignificant, measured values for height $0.61 \mathrm{~cm} \mathrm{(-8} \mathrm{\% ),}$

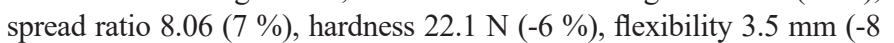
$\%)$, toughness $42.1 \mathrm{~N}(-11 \%)$, and odour $9(8 \%)$ were in a reasonable agreement with predicted values. Thus, biscuits with optimised mixture of cocoa, grape and aronia pomaces powders were proven better than the control in terms of lower hardness (-23\%) and toughness (-19\%), bigger spread ratio, and the same overall acceptability. General opinions on the flavour, colour, texture and overall acceptability of optimised biscuits were highly positive (in category 'liked very much') indicating that aronia and grape pomace powders could be used as partial substitutes for cocoa powder in biscuits. 


\section{Microbiological evaluation}

The shelf-life of food including biscuits may be compromised by the growth of food spoilers and foodborne pathogens. Fruit pomaces and cocoa powder possess different phenolic compounds, which have antimicrobial activity (Galanakis, 2017). For example, grape pomace, used for preparation of this biscuits, was proposed as an interesting source of natural products to extend the shelf-life of different foodstuff such as meat and meat products, fish products, seafood, and cheese (Galanakis, 2017). Salmonella, Enterobacteriaceae, and Staphylococcus were not detected in the optimised and control biscuits during 6 months of storage. Moreover, no moulds or yeasts were found after six months of storage. Total plate count was growing gradually from $9.2 \times 10^{1} \mathrm{cfu} / \mathrm{g}$ after one month of storage to $5 \times 10^{4} \mathrm{cfu} / \mathrm{g}$ after six months of storage in both control and optimised biscuits. This depicts that total viable count of the biscuits was a bit higher than $10000 \mathrm{cfu} / \mathrm{g}$ which is recommended in Croatian National Guidelines on microbiological criteria for foodstuffs (2011). Still, we can conclude that both samples were within the microbial limit standard and thus safe for consumption during six months of storage.

\section{Conclusions}

In this research, we optimised wholemeal biscuit formulation with grape and aronia pomaces as partial substitutes for cocoa powder using mixture design and desirability function. Biscuits height, spread ratio, hardness, flexibility, toughness, appearance, and odour were not significantly influenced by the mixture composition. On the other hand, the diameter of biscuits was significantly dependent on interactions between all three mixture components. Overall acceptability of biscuits was mostly driven by their flavour which was better liked when cocoa powder prevailed in the mixture. Still, biscuits with the optimised mixture of cocoa $(76.4 \%)$, grape pomace $(17.5 \%)$ and aronia pomace $(6.1 \%)$ were proven better than the control $(100 \%$ cocoa) in terms of decreased hardness $(-23 \%)$ and toughness $(-19 \%)$, having the same sensory acceptability. The findings of this study indicate that powdered grape and aronia pomaces as sustainable resources could successfully substitute up to $24 \%$ of cocoa powder in the production of wholemeal biscuits. Future studies should investigate different sustainable sources for substituting cocoa powder in fine bakery products.

\section{Acknowledgements}

The authors wish to thank Davorka Šipek and Vlado Remenar for providing us grape and aronia pomace. Authors also thank Lidija Drobac, Darjan Pipic and Goran Bosanac for the valuable help and assistance in the laboratory.

\section{References}

Acun S., Gül, H. (2014) Effects of grape pomace and grape seed flours on cookie quality. Quality Assurance and Safety of Crops and Foods, 6 (1) 81- 88 .

Ajila C.M., Leelavathi K., Prasada Rao, U.J.S. (2008) Improvement of dietary fiber content and antioxidant properties in soft dough biscuits with the incorporation of mango peel powder. Journal of Cereal Science, 48 (2) 319-326.

AACC (1999) Method 10-50.05. Baking quality of cookie flour. Approved methods of analysis (11th Ed.). American Association of Cereal Chemists AACC International, St. Paul, MN, USA.

Barroso L.S., de Oliveira V.R., Garcia A.V., Doneda D., Ourique L.A., Vieira M.M. (2015) Physicochemical and sensory evaluation of sandwich cookies made with carob powder. Advance Journal of Food Science and Technology, 9 (4) 290-295.

Chakraborty S.K., Kumbhar B.K., Chakraborty S, Yadav P., Prakash Sharma H. (2010) Colour characteristics and overall acceptability of fibre enriched biscuits: a response surface approach. International Journal of Food Engineering, 6 (6) 6.

COMMISSION REGULATION (EC) No 2073/2005 of 15 November 2005 on microbiological criteria for foodstuffs.

Croatian National Guidelines on microbiological criteria for food stuffs (2011) $3^{\text {rd }}$ ed, Ministry of Agriculture, Zagreb, Croatia.

Crofton E.C., Markey A., Scannell A.G.M. (2013) Consumers' expectations and needs towards healthy cereal based snacks: An exploratory study among Irish adults. British Food Journal, 115 (8) 1130-1148.

Curutchet A., Cozzano S., Tárrega A., Arcia P. (2019) Blueberry pomace as a source of antioxidant fibre in cookies: Consumer's expectations and critical attributes for developing a new product. Food Science and Technology International, 25 (8) 642-648.

Čukelj N., Putnik P., Novotni D., Ajredini S., Voučko B., Ćurić, D. (2016) Market potential of lignans and omega-3 functional cookies. British Food Journal, 118 (10) 2420-2433.

Fadel H.M., Abdel Mageed M.A., Abdel Samad A.K.M.E., Lotfy S.N. (2006) Cocoa substitute: Evaluation of sensory qualities and flavour stability. European Food Research and Technology, 223 (1) 125-131.

Galanakis C.M. (2012) Recovery of high added-value components from food wastes: conventional, emerging technologies and commercialized applications. Trends in Food Science \& Technology, 26 (2) 68-87.

Galanakis C.M. (2017) Handbook of grape processing by products sustainable solutions. $1^{\text {st }}$ ed. London: Academic press.

ISO 6579-1:2017 (2017) Horizontal method for the detection, enumeration and serotyping of Salmonella spp. Geneva, Switzerland: International Organization for Standardization (ISO).

Karnopp A. R., Figueroa A. M., Los P. R., Teles J. C., Simões D. R. S., Barana A. C., Kubiaki F. T., de Oliveiea J. G. B., Granato D. (2015) Effects of whole-wheat flour and bordeaux grape pomace (Vitis labrusca L.) on the sensory, physicochemical and functional properties of cookies. Ciência e Tecnologia de Alimentos, 35(4) 750-756.

Khanal R.C., Howard L.R., Brownmiller C.R., Prior, R.L. (2009) Influence of extrusion processing on procyanidin composition and total anthocyanin contents of blueberry pomace. Journal of Food Science, 74 (2) H52-H58.

Konstantas A., Stamford L., Azapagic A. (2019) Evaluation of environmental sustainability of biscuits at the product and sectoral levels. Journal of Cleaner Production, 230 1217-1228.

Kuchtova V., Karovičova J., Kohajdova Z., Minarovičova L., Kimličkova, V. (2016) Effects of white grape preparation on sensory quality of cookies. 
Acta Chimica Slovaca, 9 (2) 84-88.

Loullis A., Pinakoulaki E. (2018) Carob as cocoa substitute: a review on composition, health benefits and food applications. European Food Research and Technology, 244 (6) 959-977.

Mamat H., Hill S.E. (2018) Structural and functional properties of major ingredients of biscuit. International Food Research Journal 25(2) 462-471. Manley D. (2000) Technology of biscuits, crackers and cookies. $3^{\text {rd }}$ ed. Cambridge: Woodhead Publishing Limited.

Mildner-Szkudlarz S., Bajerska J., Zawirska-Wojtasiak R., Górecka D. (2013) White grape pomace as a source of dietary fibre and polyphenols and its effect on physical and nutraceutical characteristics of wheat biscuits. Journal of the Science of Food and Agriculture, 93 (2) $389-95$.

Palocci C.S., Chronopoulou L. (2015) Supercritical fluid extraction of pharmaceutic compounds from waste materials derived from vinification processes. In: Fruit and Pomace Extracts: Biological Activity, Potential Applications and Beneficial Health Effects, J.P. Owen (Ed). Future Medicine Ltd., p. 69-79. London: Nova Science Publishers.

Pathare P.B., Opara U.L., Al-Said F.A.J. (2013) Colour Measurement and Analysis in Fresh and Processed Foods: A Review. Food and Bioprocess Technology, 6 (1) 36-60.

Pawłowska K., Kuligowski M., Jasińska-Kuligowska I., Kidon M., Siger A., Rudzinsk M., Nowak, J. (2018) Effect of replacing cocoa powder by carob powder in the muffins on sensory and physicochemical properties. Plant Foods for Human Nutrition, 73 196-202.

Prokopov T., Goranova Z., Baeva M., Slavov A., Galanakis M.C. (2015) Effects of powder from white cabbage outer leaves on sponge cake quality. International Agrophysis, 29 (4) 493-500.

Rikon S.M., del Valle F. (1982) US Patent No. 4,335,153. Imitation cocoa powder and method of preparing same. Washington, DC: U.S. Patent Office. Rosa C.S., Tessele K., Prestes R.C., Silveira M., Franco F. (2015) Effect of substituting of cocoa powder for carob flour in cakes made with soy and banana flours. International Food Research Journal, 22 (5) 2111-2118.

Silanikove N., Landau S., Or D., Kababya D., Bruckental I., Nitsan, Z. (2006) Analytical approach and effects of condensed tannins in carob pods (Ceratonia siliqua) on feed intake, digestive and metabolic responses of kids. Livestock Science, 99 (1) 29-38.

Singh A., Rana I., Sahi N.C., Lohani U.C., Chand, K. (2012) Optimization of process variables for preparation of apple pomace - black soyflour based biscuits. International Journal of Food, Agriculture and Veterinary Sciences, 2 (1) 101-106.

Svensson L. (2012) Design and performance of small scale sensory consumer tests. University of Agricultural Sciences: The Faculty of Natural Resources and Agricultural Sciences, Uppsala. Retrived from Uppsala website: http://stud.epsilon.slu.se/50 45/1

Šarić B., Mišan A., Mandić A., Nedeljković N., Pojić M., Pestorić M., Đilas S. (2016) Valorisation of raspberry and blueberry pomace through the formulation of value-added gluten-free cookies. Journal of Food Science and Technology, 53 (2) 1140-1150.

Turksoy S. and Ozkaya B. (2011) Pumpkin and carrot pomace powders as a source of dietary fiber and their effects on the mixing properties of wheat flour dough and cookie quality. Food Science and Technology Research, 17 (6) 545-553.

Walker R., Tseng A., Cavender G.A., Zhao Y., Ross, A. 2014. Physicochemical, nutritional, and sensory qualities of wine grape pomace fortified baked goods. Journal of Food Science, 79 (9) 1811-1822. 